\title{
Comparative analysis of bonding mechanism in solid state metal working processes
}

\author{
G. Buffa ${ }^{1, a}$, S. Pellegrino ${ }^{1}$, E. Lo Valvo ${ }^{1}$, L. Fratini ${ }^{1}$ \\ ${ }^{1}$ University of Palermo, Department of chemical engineering, management, computer, mechanical-DICGIM, Viale delle Scienze 128, 90128 \\ Palermo, Italy, http://www.dicgim.unipa.it
}

\begin{abstract}
The Piwnik and Plata pressure-time bonding criterion was applied to Friction Stir Welding, Linear Friction Welding, Porthole Extrusion and Roll Bonding. A neural network was set up, trained and used to predict the bonding occurrence starting from the main field variable distributions calculated through specific numerical models developed for each process. The analysis of the results permitted to predict the occurrence of solid bonding and to highlight differences and analogies between the processes in order to obtain sound solid welds.
\end{abstract}

\section{Introduction}

Solid state bonding processes as Friction Stir Welding (FSW), Linear Friction Welding (LFW), Porthole Die Extrusion (PDE), and Accumulative Roll Bonding (ARB) are currently widely used in industry [1] due to their ability of not requiring the melting of the material, making them particularly suitable for all those materials difficult to weld with traditional techniques, such as aluminum, magnesium and titanium alloys.

However, often the process design is based on the knowledge of the operator rather than upon scientific knowledge. In fact, solid bonding occurrence can hardly be predicted by FEM models of a given manufacturing processes due to the different physical phenomena taking place at the same time and affecting the onset of solid state welding. The extrusion of hollow or semi-hollow profiles (PDE) is a common industrial process which is often made by using the "porthole die" [2]. During the process the material separates into two or more seams. The two material flows eventually join in the welding chamber, under proper conditions of temperature and pressure. If the appropriate conditions of temperature and pressure are achieved, the welding process takes place in a solid state condition. Welding lines in the longitudinal extruded profiles are determined and the quality of the extruded joints is closely related to the efficiency of the mechanical longitudinal welds [3]. Accumulative Roll Bonding (ARB) is a process in which two sheets metal are overlapped and rolled with thickness reduction of $50 \%$ [4]. The two metal sheets, by passing through the rollers, are welded forming the final laminate, with reduced thickness compared to the original sheets, due to the rolling ratio imposed. Also in this process, solid bonding occurs under proper conditions of temperature and pressure.
Friction Stir Welding (FSW) is a solid state welding process patented by The Welding Institute in Cambridge (UK) in 1991 [5]. Solid welding of the sheet metals is produced by the heat generated by the friction between the tool and the sheets [6]. This process is becoming increasingly important due to the exceptional results obtained for the mechanical junction of materials, such as aluminum alloys, referred to as "not weldable" by conventional welding technologies. A key factor to obtain sound joints is the proper choice of the process parameters, which in turn affects the bonding conditions determining the mechanical resistance of the obtained joints. During the process, the tool rotation speed (R) and feed rate $(\mathrm{V})$, determining the specific thermal contribution conferred to the joint, are combined in a way that an asymmetric metal flow is obtained. In particular, an advancing side and a retreating side are observed: the former being characterized by the "positive" combination of the tool feed rate and of the peripheral tool velocity, the latter having velocity vectors of feed and rotation opposite each other [7].

Proper values of the main field variables, as temperature, strain and strain rate are needed in order to get the final effective bonding [8]. The Linear Friction Welding process (LFW) is a solid-state joining process [9] in which the two pieces are placed in contact by means of axial force and, at the same, a reciprocating linear motion is activated [10]. The formation of a uniform weld bead is obtained due to the heat generated by the friction forces work. The weld bead consists of the plasticized material, part of which is ejected from the interface as flash. When a reciprocating motion occurs under an assigned pressure, a significant amount of heat is produced. Due to the concurrent effect of oscillation and pressure, the material at the interface is forced to flow out of the joint. Part of this plasticized material,

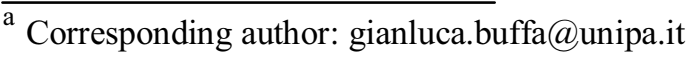


called flash, is removed during welding. In this way, any pre oxidized surface and other impurities are removed through the flash, allowing intimate contact between the materials and, hence, the creation of the joint.

A few research groups worked on the development of a solid bonding criterion for accumulative roll bonding (ARB) and porthole die extrusion (PDE). The first criterion in literature was proposed by Akeret [11]. In his study, the author proposed a simple formulation taking into account just the maximum value of the contact pressure. Due to its extreme simplicity, the criterion was widely used in the past years. More recently, Azushima [12] successfully used this approach in the prediction of solid bonding in ARB of different metals. Unfortunately, due to its extreme simplicity, this criterion is not suitable for processes characterized by a more complex mechanics, namely PDE, FSW and LFW. Piwnik and Plata [13] proposed an enhanced formulation of the welding criterion based on the integral on time of the ratio between the contact pressure and the material flow stress. Due to the variation of the flow stress during the time in which material self-contact occurs, it can be stated that this criterion takes into account the local and instant values of temperature, strain, strain rate and pressure.

A few studies can be found in literature as examples of successful application of the Piwnik and Plata criterion. Ceretti [14] identified the threshold value, as a function of temperature, for aluminum alloy AA6061 during ARB experiments. Then, the authors validated the formulation obtained though PDE tests. The aim of the paper is the development of an integrated numerical tool able to predict the occurrence of solid bonding and the quality of a weld as a function of the technological parameters of the processes. In particular, the FEM models allowed to correlate the process parameters to the main field variables distributions. The latter were used by the NN in order to predict the occurrence of solid bonding. Different process input parameters have been used in order to obtain different qualities of the welds, including sound and not welded joints. A numerical campaign was developed for each process to calculate the main field variables, i.e. temperature, strain, strain rate and stress. A Neural Network (NN) for the four different processes PDE, ARB and FSW and LFW was developed and integrated into the FEM tool. The $\mathrm{NN}$ is able to provide, for each point identified of the transverse sections of the joints, a qualitative output indicating occurrence of solid state welding as well as a quantitative output based on the Piwnik and Plata criterion indicating the level of "soundness" of the weld.

\section{Experimental data}

\subsection{Friction stir welding}

The effects of the operating parameters have been highlighted on some of the fundamental aspects of the FSW process in order to obtain sound joints and defective joints [15]. The sheets thickness was $2.5 \mathrm{~mm}$. Butt joints were obtained out of aluminum alloys AA6061-T6,
$100 \mathrm{~mm} \times 200 \mathrm{~mm}$ in dimensions. The sets of geometric and technological parameters were chosen in order to obtain intentionally different quality of welded joints (Table 1). As regards to the technological parameters, fixed tilt angle of the tool of $2^{\circ}$ was selected.

Table 1 FSW parameters used for the numerical campaign

\begin{tabular}{ll}
\hline Parameter & Value \\
\hline Feed rate V [mm/min] & $100,200,400$ \\
Rotational speed R [rpm] & 500,1000 \\
Tilt angle & $2^{\circ}$ \\
Tool plunge $[\mathrm{mm}]$ & 2.2 \\
\hline
\end{tabular}

\subsection{Accumulative roll bonding}

As far as the Roll Bonding process is regarded, experimental data were taken from the paper by D'Urso et al [16]. In the paper, two sheets were rolled together to a final welded sheet thickness of $10 \mathrm{~mm}$. The tests were carried out at the varying of the initial sheets thickness, in order to obtain different rolling ratio values - ranging from $50 \%$ to $83.3 \%$ - and of sheets temperature ranging from $300{ }^{\circ} \mathrm{C}$ to $530{ }^{\circ} \mathrm{C}$ (table 2).

Table 2 Roll Bonding parameters used

\begin{tabular}{ccl}
\hline $\begin{array}{c}\text { thickness } \\
{[\mathbf{m m}]}\end{array}$ & $\begin{array}{c}\text { Threshold } \\
{\left[{ }^{\boldsymbol{C}} \boldsymbol{C}\right]}\end{array}$ & \multicolumn{1}{c}{ Temperature $\left[{ }^{\circ} \boldsymbol{C}\right]$} \\
\hline 12 & 520 & $530,510,490,470$. \\
13 & 490 & $530,510,490,470,450,430$. \\
14 & 420 & $470,450,430,410,390,360$. \\
15 & 380 & $430,410,390,360,330,300$. \\
16 & 340 & $410,390,360,330,300$. \\
18 & 320 & $390,360,330,300$. \\
\hline 20 & 300 & $360,330,300$. \\
\hline
\end{tabular}

\subsection{Porthole die extrusion}

Experimental data for the PDE process were taken from the paper by Ceretti et al. [17]. In particular, PDE tests were conducted with varying Welding Chamber Height (WCH) and Rib Thickness (RT) on AA6061 aluminum alloy. Other technological and geometrical parameters were kept constant (table 3). The weld limit was experimentally obtained and numerical simulations were run for each case studying in order to highlight the process conditions resulting in effective bonding or in defective parts.

Table 3 PDE parameters used for the numerical campaign

\begin{tabular}{ll}
\hline Parameter & Value \\
\hline Welding chamber width $[\mathrm{mm}]$ & 140 \\
\hline Hole Width $[\mathrm{mm}]$ & 30 \\
Welding chamber height $[\mathbf{m m}]$ & 30,50 \\
Rib Thickness $[\mathrm{mm}]$ & 30,60 \\
Billet temperature $\left[{ }^{\circ} \mathbf{C}\right]$ & 480 \\
Dies Temperature $\left[{ }^{\circ} \mathbf{C}\right]$ & 450 \\
Punch Speed $[\mathbf{m m} / \mathbf{s}]$ & 8 \\
\hline
\end{tabular}




\subsection{Linear friction welding}

LFW joints were obtained out of AA6061-T6 aluminum alloy specimens. In order to develop the experimental campaign, a previously in-house designed and built LFW machine was equipped with measuring sensors [18]. The contact surface of the utilized specimens was $10 \times 7 \mathrm{~mm}^{2}$ [19]. The tests were carried out using varying oscillation and contact pressure. In particular, three values of oscillation frequency and five values of contact pressure were selected. Process time and oscillation amplitude were kept constant for all the tests. In this way, a total of 15 different welding configurations were investigated (Table 4).

Table 4 LFW parameters used for the numerical campaign

\begin{tabular}{ll}
\hline Parameter & Value \\
\hline Frequency f [Hz] & $36,45,58$ \\
Pressure p [MPa] & $20,30,40,50,60$ \\
Amplitude A [mm] & 2 \\
Time t $[\mathbf{s e c}]$ & 1.25 \\
\hline
\end{tabular}

\section{Numerical Models for the Considered Processes}

The commercial FEA software DEFORM- $3 \mathrm{D}^{\mathrm{TM}}$, Lagrangian implicit code designed for metal forming processes, is used to model the four processes. A rigid visco-plastic material model was utilized to simulate the four processes. In particular, a strain, strain rate and temperature dependent flow stress was utilized [20]. For the thermal characteristics of the AA6061 aluminum alloys taken into account, the following values were utilized: thermal conductivity $\mathrm{k} 1=166\left[\mathrm{~N} /\left(\mathrm{s}{ }^{\circ} \mathrm{C}\right)\right]$ and thermal capacity $\mathrm{c}=2.3\left[\mathrm{~N} /\left(\mathrm{mm}^{2}{ }^{\circ} \mathrm{C}\right)\right]$ taken from literature [15]. No variation of $\mathrm{k} 1$ and $\mathrm{c}$ with temperature was taken into account; this assumption linearizes the thermal equation and results in better convergence. Additionally, thermal exchange with environment was considered, with coefficient equal to $0.02\left[\mathrm{~N} /\left(\mathrm{mm}-\mathrm{s}^{\circ}{ }^{\circ} \mathrm{C}\right)\right]$.

\subsection{Friction stir welding model}

A fully 3D FEM model for the FSW process is proposed [21], that is thermo-mechanically coupled and with rigidviscoplastic material behavior.

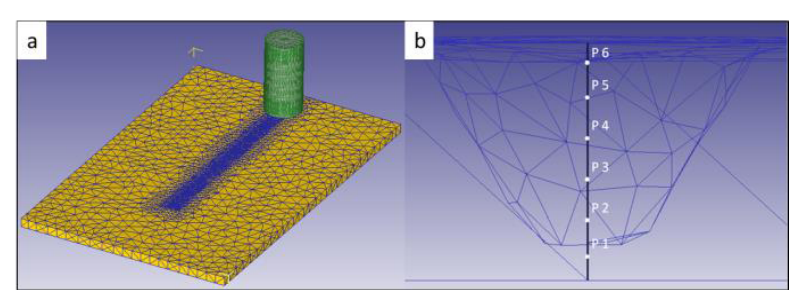

Figure 1 a) FSW model; b) Initial position of the identified points
A unique feature of this model is the representation of sheet seam (abutting edges) as a continuum. This continuum assumption avoids the numerical instabilities resulting from the discontinuities present at the edge of the two sheets. Predicted results are compared with the experimental data to validate this model. The workpiece is modeled as a rigid visco-plastic material, and the welding tool is assumed rigid. This assumption is reasonable as the yield strength of the sheet (conventionally aluminum alloy) is significantly lower than the yield strength of the tool (tool steel or carbide).

This model was first calibrated by comparing calculated force and temperature distribution with experimental results [21]. Then it was used to investigate the distribution of the main field variables in the heat affected zone and the weld nugget. The tool is modeled as a rigid object and meshed, for the thermal analysis only, with about 4,000 tetrahedral elements. The blank is meshed with about 10,000 tetrahedral elements with finer mesh along the weld seam (Fig. 1a). The clamping fixture and the backplate were taken into account by proper boundary conditions on the top and bottom surface of the blank. An adaptive remeshing algorithm is used to overcome convergence problems arising from the severe deformation the material undergoes during the process. A constant time increment of $0.001 \mathrm{~s}$ was used. A constant shear friction factor of 0.46 was used for the tool-sheet interface on the basis of a previous experimental thermal characterization and of a numerical sensitivity analysis for the shear friction factor $m$ [22]. At the end of the simulation, the material flow was investigated through the analysis of the nodes movement and the main field variables history that they experience. The "node tracking" option of the software was utilized, highlighting, for a set of nodes initially placed along the sheets separation line in a transverse section, their final position after deformation. The identified points were monitored throughout the process: six points equally spaced along the joint thickness were identified as shown in Fig. 1b. The reference transverse section was taken after $40 \mathrm{~mm}$ of weld length, when the process has already entered a steady state and the obtained data are free from transient effects.

\subsection{Accumulative roll bonding model}

The 2D numerical model for the Roll Bonding process was developed starting from the experimental campaign developed by D'Urso et al. [23].

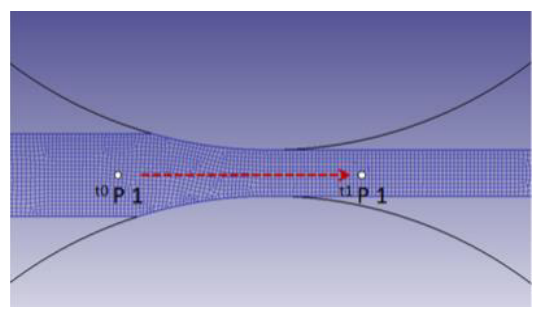

Figure 2 Observation point on the sheets separation line for the roll bonding process 
A plane strain approach was selected and, similarly to what was done for the previous model, the two sheets were modeled as a "single block". Two refinement mesh windows were used close to the rolls in order to get an average element size of $0.2 \mathrm{~mm}$ in that area. A constant time increment of $0.001 \mathrm{~s}$ was used. A shear friction model was adopted with value equal to 0.8 . The heat exchange coefficient with environment was set equal to zero because of the isothermal conditions of the experimental tests. An initial temperature corresponding to the considered case study condition was given to the sheet. Finally, due to the stationary conditions of the rolling process, just one point for each case study was taken into account for the analysis of the field variables histories leading to the bonding. The point $\mathrm{P} 1$ was placed along the horizontal symmetry line, i.e. on the separation surface between the two sheets, as illustrated in Figure 2 together with the process model.

\subsection{Porthole die extrusion model}

The numerical model for PDE was developed starting from the results found in the paper [17] by Ceretti et al. as indicated in Table 3. As far as the modeling of the process is regarded, a 2D model was developed taking advantage of the existing symmetry. A refining mesh window was placed close to the rib with minimum element size of about $0.2 \mathrm{~mm}$ (Fig. $3 \mathrm{a}$ and b). It is worth noticing that a simplified configuration of the process was used, based on the assumptions adopted in [17], in which the bridges are absent. However, the features associated with welding in PDE are present in the model, making it a relevant yet simple case study for the scope of the paper. A constant time increment of $0.001 \mathrm{~s}$ was used. A shear friction model was selected with friction factor equal to 0.4 . (a)

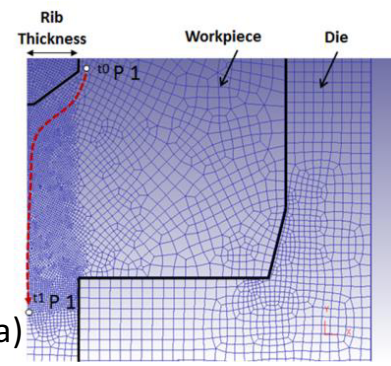

(b)

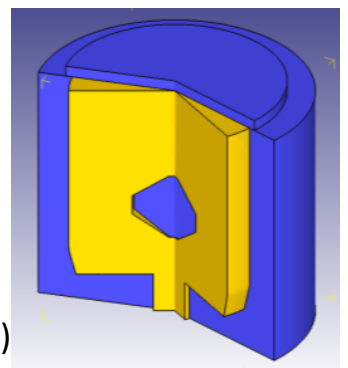

Figure 3 (a)Sketch of the observation point flow for the PDE process and (b) 3D view of the model

Five tracking points have been considered for the monitoring of the field variables evolution. Finally, a slightly different approach was followed for the PDE process. The five considered tracking points were placed along the bonding line, i.e. that vertical symmetry axis of the process, and "tracked back" to their starting position. This approach was followed in order to be sure that the observed points are involved in the bonding phenomenon at the contact interface between the two adjoining metal flows.

\subsection{Linear friction welding model}

A 3D model was developed for the LFW process. The workpiece, reproducing the top specimen (Fig. 4a,) was modeled as a rigid visco-plastic object. A longitudinal symmetry plane, parallel to the oscillation direction (red transparent plane in figure 4a) was used in order to model just half of the top specimen thus saving CPU time. Further details on model setup can be found in [24]. The actual dimensions of the top specimen were reproduced. The bottom specimen was modeled as a rigid plate $60 \mathrm{~mm}$ in width, $2.5 \mathrm{~mm}$ in thickness and $90 \mathrm{~mm}$ in length. With this assumption, significant saving in CPU time can be achieved with acceptable accuracy in the field variables prediction [24]. This choice was made in order to simplify the contact condition avoiding numerical instabilities due to the deformable-deformable object contact.

The software allows only discretization with tetrahedral elements, (linear shape functions). It was necessary to introduce a denser discretization close to the welding surface where high gradient of the main field variables exist. Additionally, a re-meshing referring volume was identified all along the specimen movement. Furthermore, it was necessary to make preliminary tests, with increasing mesh density, to determine the optimal dimension of the finite elements in these critical areas. Consequently, two windows with different discretization were created. The model has approximately 32,000 elements with the smallest elements characterized by edge of about $0.15 \mathrm{~mm}$. The specimen is constrained against $\mathrm{x}$ and $\mathrm{y}$ translation for $7 / 8$ of its height for increased stability, while an axial load was imposed on the top surface of the workpiece along the $\mathrm{z}$ axis.

A friction window was used to simulate the real physical contact conditions, i.e. the top specimen contact surface varies with time according to the oscillation frequency. Outside the friction window, the constant shear friction factor was set equal to zero. A constant time increment of $0.0001 \mathrm{~s}$ was used for all the simulations. No heat exchange was considered between the top and bottom objects because of the symmetry of the process. The oscillation was assigned to the bottom specimen while the pressure was applied to the upper surface of the top specimen.

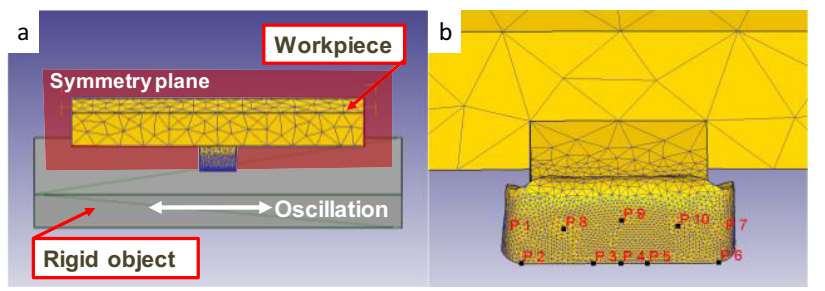

Figure 4 a) LFW model; b) Final position of the identified points

At the end of the simulation the material flow was investigated through the analysis of the nodes position and the main field variables history that they experience. The "point tracking" option of the software was utilized, highlighting, for a set of points initially placed at the contact interface, their final position after deformation. 
Ten points were identified and monitored throughout the process as shown in Figure $4 \mathrm{~b}$ ( please notice that Fig $4 \mathrm{~b}$ refers to a bottom view rotated of about $45^{\circ}$ with respect to an horizontal axis)

\section{Numerical results}

In order to build the training data set for the neural network, the material flow has been studied for each of the numerical simulations implemented, for each processes. In this study the pressure-time (W) welding criterion was utilized:

$$
W=\int_{t 0}^{t 1} \frac{p}{\theta} d t
$$

For the aluminum alloy AA6061 taken into account in to this study the $\mathrm{W}$ limit curve was identified and a regression was performed obtaining the following expression as a function of temperature [13]:

$$
W^{L I M}=13425.43 T^{-1.41}
$$

Regarding the FSW process, in order to calculate, for each of the observation points highlighted in Fig. 1b, the value of the welding criterion, the material flow occurring during the FSW process must be properly predicted. Buffa et al. [15] proved the effectiveness of the developed model for the prediction of the material flow by comparing the calculated results with experimental measurements of the zig-zag line due to the oxides particles dispersed in the transverse section. Following the approach proposed in the above cited paper, the reference points were tracked during the process. It is worth noticing that the observation time interval begins as the points experience non-zero pressure values, i.e. before the tool reaches the reference transverse section.

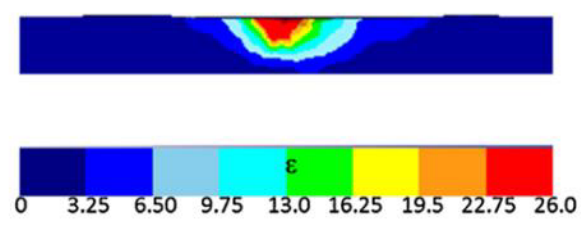

Figure 5 Strain distribution in the specimen

The field variable distribution highlights some of the characteristics of the FSW process: strain is not symmetric with respect to the welding line (Fig. 5). The strain peaks are shifted towards the advancing side. As far as the roll bonding process is regarded, a similar approach used for the FSW process was followed. In particular, the selected point $\mathrm{P} 1$ lies on the initial separation line between the sheets (Figure 2, initial time t0) and, during the process, moves horizontally as indicated by the red dotted line in Figure 2. The final position (t1) corresponds to the time increment at which the bonding process is completed. For the roll bonding process the pressure that generates the welding can be easily calculated considering the stress in the vertical direction.

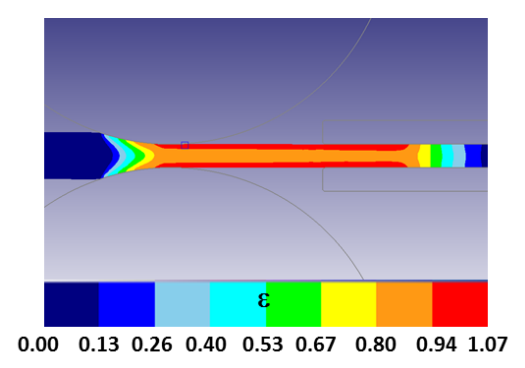

Figure 6 Strain distribution in the specimen

Smaller strain values are observed, the similar trends of the observed field variables with respect to FSW show that the two techniques, characterized by totally different process mechanics, induce the same solicitations in the material in order to obtain the solid bonding. A slightly different approach was followed for the PDE process. The five considered tracking points were placed along the bonding line, i.e. that vertical symmetry axis of the process, and "tracked back" to their starting position. This approach was followed in order to be sure that the observed points are involved in the bonding phenomenon at the contact interface between the two adjoining metal flows. Fig. 7a shows the strain distribution during the process. It is worth noticing that a peak of strain is found in the die corner. As it is shown in Fig. 7b, this is due to a flow vortex taking place in this area due to flat geometry of the bottom die surface. Additionally, it should be observed that some slave penetration in the master surface occurs in this area. This numerical issue contributes to slightly decrease the actual pressure in the welding chamber. (a)

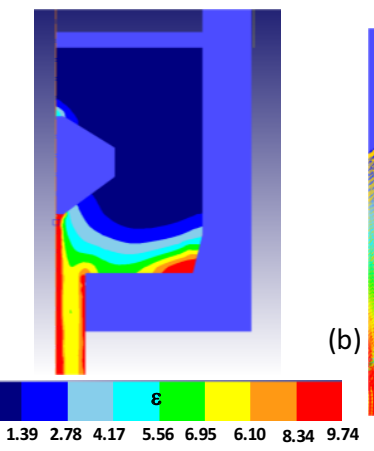

b)

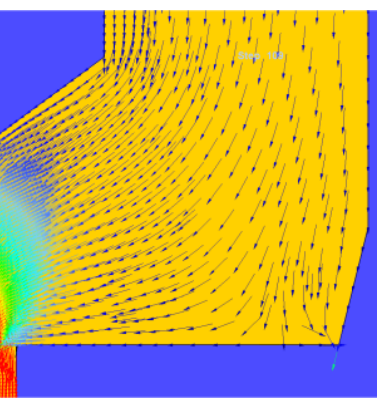

Figure 7 (a) strain distribution in the specimen and (b) velocity vectors

Finally, regarding the LFW process, a time step of $0.01 \mathrm{~s}$ was selected to extract the data for each of the identified points (Fig. 4b) and calculate the sum indicated in Eq. 1. In order to build the training data set for the neural network, the value of the welding criterion was calculated for each of the observation points and the final position of the observation points was highlighted (Fig. 4b).

In this way, 150 values were obtained. As already mentioned, due to the relatively simple material flow, ten tracking point for each process condition were utilized. In the linear friction welding process the pressure $p$ generating the solid bonding (Eq. 1) can be easily 
calculated considering the actual contact pressure at interface.



Figure 8 Strain distribution in the specimen

Figure 8 shows the strain distribution in the specimen, at the end of the process. Maximum strain is reached at the center of the contact inteterface. The field variable distribution highlight some of the characteristics of the linear friction welding process: the strain is higher at the welding surface. Two main zones can be identified regarding the effective strain: the zone still in in contact with the bottom specimen experience very high strain values; the zones of the material belonging to the flash, which have been in contact with the bottom specimen for a smaller time, show lower values.

\section{Neural Network set up}

Based on these observations, the development of the neural network has been evaluated as the most effective for the prediction of the bonding phenomenon. The neural network was designed with the aim to get two separated outputs: a qualitative output, indicating if the bonding process for the considered observation point occurred; a quantitative output, indicating the level of "soundness" of the bonding. In order to build the latter indicator, a parameter $\mathrm{Q}$ was defined starting from the Piwnik and Plata parameter $\mathrm{W}$ for each observed point i:

$$
Q_{i}=\frac{w_{i}}{w_{i}^{L I M}}
$$

Where

$$
W=\int_{\text {to }}^{t 1} \frac{p}{g} d t \cong \Sigma_{j} \frac{p_{j}}{\theta_{j}} \Delta t_{j}
$$

$\mathrm{W}^{\mathrm{LIM}}$ is the critical value of $\mathrm{W}$ that must be reached in order to obtain the solid bonding (eq. 2). It is worthy of notice that a summation was used instead of the integral due to the discrete time increments $\mathrm{j}$ used for the simulations. The training data set was build calculating an average value of the considered field variable for a specific tracking point and a given process, according to the following:

$$
T_{i}=\frac{\int_{\mathrm{t} 0}^{\mathrm{t} 1} T d t}{t 1-t 0} \cong \sum_{j} \frac{T_{j} \Delta t_{j}}{t 1-t 0}
$$

$$
\begin{aligned}
& p_{i}=\frac{\int_{t a}^{t 1} p d t}{t 1-t 0} \cong \sum_{j} \frac{p_{j} \Delta t_{j}}{t 1-t 0} \\
& \varepsilon_{i}=\frac{\int_{t 0}^{t 1} \varepsilon d t}{t 1-t 0} \cong \sum_{j} \frac{\varepsilon_{j} \Delta t_{j}}{t 1-t 0} \\
& \varepsilon_{i}=\frac{\int_{t 0}^{t 1} \varepsilon d t}{t 1-t 0} \cong \sum_{j} \frac{\varepsilon_{j} \Delta t_{j}}{t 1-t 0}
\end{aligned}
$$

In this way, 36 data were derived from FSW (6 points, 6 process conditions), 34 from ARB (one point, 34 process conditions), 20 from $\mathrm{PDE}$ ( 5 points, 4 process conditions) and 150 from LFW, corresponding to 15 process conditions and 10 points for each process. The network architecture consists of 5 hidden layers: the input layer is characterized by 4 neurons corresponding to the average values of temperature, strain, strain rate and pressure as calculated in equations 5-8. Three hidden layers were used, with 5, 4 and 3 neurons, respectively. Finally, an output layer, with 2 neurons corresponding to the qualitative "welded-not welded" output and the quantitative Q parameter is found. All the data were normalized to assume values between -1 and 1 . Each layer was fully connected to the next and, according to the back-propagation rule, the weights of the connections linking a neuron belonging to a certain layer to a neuron belonging to the next were adjusted in the learning stage with the aim to minimize the error between the desired output and the calculated one. The topology of the utilized network, reported in figure 9, was determined on the basis of an optimization procedure aimed to improve the network performances.

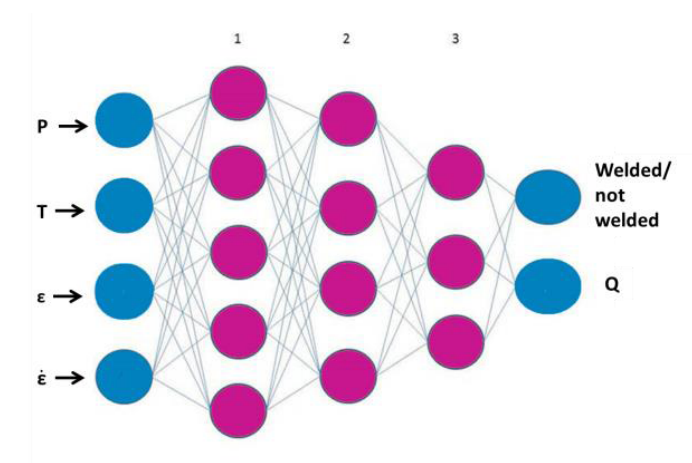

Figure 9 Architecture of the Utilized Neural Network

As far as the training is regarded, it was developed providing to the network the input data coming from the simulations, as previously described; target data came from the experimental observations (welded/not-welded qualitative output) and combined experimental and numerical results (Q parameter). About $7 \%$ of the available input and target data, i.e. 16 values, were used for the test of the network. In particular, 4 observation points for each process were selected, including both sound and not effective bonding.

\section{Neural Network Results}

Table 5 shows the 16 data used for the test of the NN. For each observation point, the correspondent process 
parameters are given together with the target output. As far as FSW is regarded, points P1 and P2, namely the closest points to the bottom of the joint, have been chosen for different process conditions. As a matter of fact, when insufficient heat is given to a joint, the so called tunnel defect is found at the advancing side close to the bottom tip of the tool pin.

Table 5 Observation points selected for the test of the developed Neural Network

\begin{tabular}{|c|c|c|c|c|c|}
\hline Id & Point & Process & $\begin{array}{c}\text { Process } \\
\text { Parameters }\end{array}$ & $\begin{array}{c}\text { Weld } \\
\text { ed }\end{array}$ & $\mathbf{Q}$ \\
\hline 1 & P 1 & PDE & $\begin{array}{c}\mathrm{WCH}=30 \mathrm{~mm} \\
\mathrm{RT}=30 \mathrm{~mm}\end{array}$ & $\mathrm{~N}$ & 0.27 \\
\hline 2 & P 2 & PDE & $\begin{array}{c}\mathrm{WCH}=30 \mathrm{~mm} \\
\mathrm{RT}=60 \mathrm{~mm}\end{array}$ & $\mathrm{~N}$ & 0.30 \\
\hline 3 & P 2 & PDE & $\begin{array}{c}\mathrm{WCH}=50 \mathrm{~mm} \\
\mathrm{RT}=60 \mathrm{~mm}\end{array}$ & $\mathrm{Y}$ & 2.73 \\
\hline 4 & P 4 & PDE & $\begin{array}{c}\mathrm{WCH}=50 \mathrm{~mm} \\
\mathrm{RT}=60 \mathrm{~mm}\end{array}$ & $\mathrm{Y}$ & 2.68 \\
\hline 5 & P 1 & $\mathrm{RB}$ & $\begin{aligned} \mathrm{Si} & =13 \mathrm{~mm} \\
\mathrm{~T} & =450^{\circ} \mathrm{C}\end{aligned}$ & $\mathrm{N}$ & 1.04 \\
\hline 6 & P 1 & $\mathrm{RB}$ & $\begin{array}{c}\mathrm{Si}=14 \mathrm{~mm} \\
\mathrm{~T}=390^{\circ} \mathrm{C}\end{array}$ & $\mathrm{N}$ & 1.04 \\
\hline 7 & P 1 & $\mathrm{RB}$ & $\begin{aligned} \mathrm{Si} & =15 \mathrm{~mm} \\
\mathrm{~T} & =300^{\circ} \mathrm{C}\end{aligned}$ & $\mathrm{N}$ & 0.87 \\
\hline 8 & P 1 & $\mathrm{RB}$ & $\begin{array}{c}\mathrm{Si}=20 \mathrm{~mm} \\
\mathrm{~T}=330^{\circ} \mathrm{C}\end{array}$ & $\mathrm{Y}$ & 1.62 \\
\hline 9 & P 1 & FSW & $\begin{array}{c}\mathrm{R}=500 \mathrm{rpm} \\
\mathrm{v}=200 \mathrm{~mm} / \mathrm{min}\end{array}$ & $\mathrm{N}$ & 0.77 \\
\hline 10 & P 1 & FSW & $\begin{array}{c}\mathrm{R}=500 \mathrm{rpm} \\
\mathrm{v}=400 \mathrm{~mm} / \mathrm{min}\end{array}$ & $\mathrm{N}$ & 0.29 \\
\hline 11 & P 2 & FSW & $\begin{array}{c}\mathrm{R}=1000 \mathrm{rpm} \\
\mathrm{v}=100 \mathrm{~mm} / \mathrm{min}\end{array}$ & Y & 3.95 \\
\hline 12 & P 1 & FSW & $\begin{array}{c}\mathrm{R}=1000 \mathrm{rpm} \\
\mathrm{v}=200 \mathrm{~mm} / \mathrm{min}\end{array}$ & $\mathrm{Y}$ & 1.36 \\
\hline 13 & P7 & LFW & $36 \mathrm{~Hz}-20 \mathrm{MPa}$ & $\mathrm{N}$ & 0.26 \\
\hline 14 & P 4 & LFW & $45 \mathrm{~Hz}-30 \mathrm{MPa}$ & $\mathrm{Y}$ & 1.98 \\
\hline 15 & P 8 & LFW & $45 \mathrm{~Hz}-30 \mathrm{MPa}$ & Y & 1.96 \\
\hline 16 & $\mathrm{P} 2$ & LFW & $58 \mathrm{~Hz}-30 \mathrm{MPa}$ & $\mathrm{Y}$ & 3.27 \\
\hline
\end{tabular}

The two outputs of the developed Neural Network are showed in figures 10 and 11 and compared with experimental results. When the Boolean network output is equal to -1 , no solid bonding is obtained. On the contrary, an output equal to 1 indicates that solid bonding was obtained.

As it can be observed, a perfect prediction of the occurrence of the bonding is found for all the case studies. Looking at the Q parameters, i.e. the discrete one, the network shows a satisfactory prediction capability (Fig. 11).

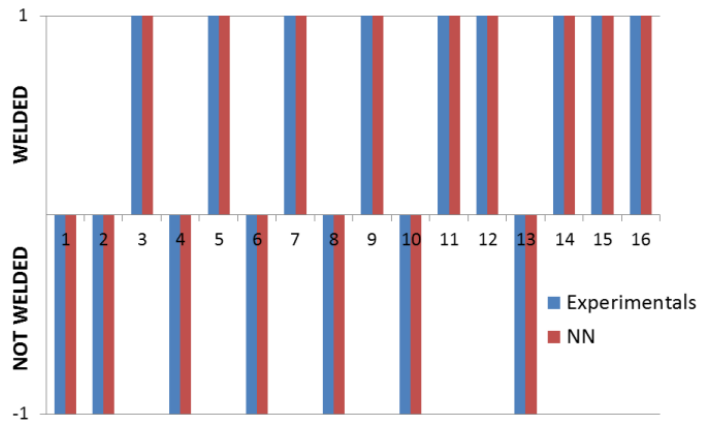

Figure 10 Neural Network response: solid bonding occurrence

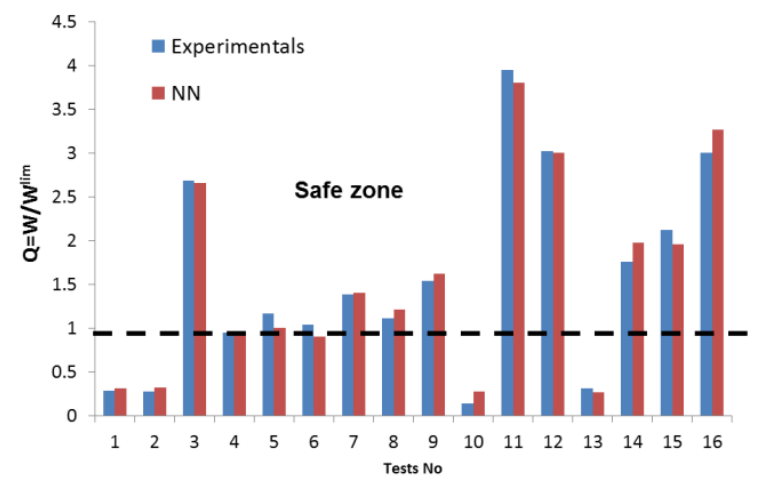

Figure 11 Neural Network response: Q parameter

The maximum difference between the calculated target and the one predicted by the NN is found for ID 5 and 6. It is noted that these points are experimentally not bonded, as correctly predicted by the qualitative network output. The prediction of the network proves to be correct in almost all of the points analyzed, with deviations from the actual values that, for most case studies, do not exceed $5 \%$. The insufficient heat area can be identified considering all the points for which $\mathrm{Q}<1$ is obtained.

\section{Conclusions}

A numerical tool aimed to predict the occurrence and the quality of solid bonding in four different manufacturing processes is presented. The results from the FE models were used to set up, train and test a dedicated neural network. The obtained output shows that the developed $\mathrm{NN}$ allows the correct identification of the occurrence of solid bonding for all the considered case studies. Additionally, the parameter $\mathrm{Q}$, index of the soundness of the weld, is predicted with maximum error lower than $5 \%$. Regardless of the peculiar process mechanics of a given process, the developed NN can be used as a process design tool in order to select proper process variables leading to the production of sound parts.

\section{References}

1. Nicholas, E.D., and Thomas, W.M., International Journal of Materials and Product Technology, 1998, 13, (1-2), pp. 45-55 
2. Valberg, H., and Malvik, T., International Journal of Materials and Product Technology, 1994, 9, (4-6), pp. 428-463

3. Liu, G., Zhou, J., and Duszczyk, J., Journal of Materials Processing Technology, 2008, 200, (1-3), pp. 185-198

4. Valiev, R.Z., Materials Science and Engineering A, 1997, 234-236, pp. 59-66

5. Thomas, M.W., Nicholas, E.D., Needham, J.C., Murch, M.G., Templesmith, P., Dawes, C.J.December 1991

6. London, B., Mahoney, M., Bingel, W., Calabrese, M., Bossi, R.H., and Waldron, D., in Editor $(\text { Ed. })^{\wedge}($ Eds.): 'Book Material flow in friction stir welding monitored with $\mathrm{Al}-\mathrm{SiC}$ and $\mathrm{Al}-\mathrm{W}$ composite markers' (2003, edn.), pp. 3-12

7. Liu, G., Murr, L.E., Niou, C.S., McClure, J.C., and Vega, F.R., Scripta Materialia, 1997, 37, (3), pp. 355-361

8. Mishra, R.S., and Ma, Z.Y., Materials Science and Engineering R: Reports, 2005, 50, (1-2), pp. 1-78

9. Crossland, B., Contemp Phys, 1971, 12, (6), pp. 559-574

10. Richter, W., Patent No. DE477084, 1929

11. Akeret, R., Proceedings of the Fifth International Aluminum Extrusion Technology Seminar, 1992, 1, pp. 319-336

12. Azushima, A., Kopp, R., Korhonen, A., Yang, D.Y., Micari, F., Lahoti, G.D., Groche, P., Yanagimoto, J., Tsuji, N., Rosochowski, A., and Yanagida, A., CIRP Annals - Manufacturing Technology, 2008, 57, (2), pp. $716-735$

13. Plata, M., and Piwnik, J., $7<$ sup $>$ th $</$ sup $>$ International Aluminum Extrusion Technology, 2000, 1, pp. 205-211

14. Ceretti, E., Fratini, L., Gagliardi, F., and Giardini, C., CIRP Annals - Manufacturing Technology, 2009, 58, (1), pp. 259-262

15. Buffa, G., Pellegrino, S., and Fratini, L., Journal of Materials Processing Technology, 2014, 214, (10), pp. 2102-2111

16. D'Urso, G., Longo, M., Giardini, C., and Ceretti, E., Proc. Technical Paper - Society of Manufacturing Engineers2012 pp. Pages

17. Ceretti, E., Mazzoni, L., and Giardini, C., International Journal of Material Forming, 2009, 2, (SUPPL. 1), pp. 101-104

18. Fratini, L., Buffa, G., Campanella, D., and La Spisa, D., Materials and Design, 2012, 40, pp. 285-291

19. Fratini, L., Buffa, G., Cammalleri, M., and Campanella, D., CIRP Annals - Manufacturing Technology, 2013, 62, (1), pp. 295-298

20. Fratini, L., and La Spisa, D., in Editor (Ed.) $)^{\wedge}($ Eds.): 'Book Numerical simulation of linear fiction welding (LFW) processes’ (2011, edn.), pp. 12841289

21. Buffa, G., Hua, J., Shivpuri, R., and Fratini, L., Materials Science and Engineering A, 2006, 419, (12), pp. 389-396

22. Fratini, L., Beccari, S., and Buffa, G., in Editor $(\text { Ed. })^{\wedge}($ Eds.): 'Book Friction stir welding fem model improvement through inverse thermal characterization' (2005, edn.), pp. 259-266

23. D'Urso, G., Longo, M., Ceretti, E., and Giardini, C., in Editor (Ed.) $)^{\wedge}$ Eds.): 'Book Coupled simulativeexperimental procedure for studying the solid state bonding phenomena' (2012, edn.), pp. 181-188

24. Buffa, G., Cammalleri, M., Campanella, D., and Fratini, L., Materials and Design, 2015, 82, pp. 238246 